Anna Klepikova

\title{
RESIDENTIAL CARE INSTITUTIONS FOR PEOPLE WITH DISABILITIES IN RUSSIA: QUESTIONING TOTALITY
}

This paper applies the concept of total institutions, introduced by Erving Goffman, to the case of special care institutions for people with intellectual disabilities in present-day Russia. These institutions represent a classic type of organization that could be studied through the lenses of the total institutions theory and demonstrate the typical features of such institutions, among them the crowded conditions in which the inmates live, a lack of privacy, universal scheduling of daily routines, strict hierarchy, a system of punishments and privileges as an instrument of control, and exploitation of inmate labour for the benefit of the institution. Drawing upon data generated by participant observation and implementing the analytical frame of symbolic interactionism at the level of routine interactions, this paper questions the 'totality' of the control mechanisms, power relations, and standardization processes found within the special care institutions for people with disabilities. One conclusion is that, although inner life in a total institution is to a certain extent subject to strict official rules, it is not limited to them. This 'total' character is manifested at the level of the structural organization of the institutions, institutional logic, and the staff's discourses, but not at the level of routine interactions. One factor challenging the totality of these institutions is the emergence of new attitudes to people with disabilities manifested by NGO volunteers, who confront the dominant patriarchal approach. In their practice they implement principles of 'normalization' ideology that helps to enhance the agency of the inmates. This enhanced agency plays an important role in managing the 'totality' in everyday interactions with the staff.

Keywords: total institution, special care institutions, mental/intellectual disability, normalization, NGO

DOI: $10.17323 / 727-0634-2019-17-3-453-464$

Anna Klepikova- PhD (Kandidat nauk) in Sociology, Research Fellow, European University at St. Petersburg, Russian Federation. Email: aklepikova@eu.spb.ru 


\section{Introduction: Conflicting Models}

This paper is devoted to the 'traditional' type of total institutions and analyses the underlife of two organizations that in Erving Goffman's terms could be called 'asylums' (Goffman 1961:3-12) and possess a number of typical features. One is a special institution for children with intellectual and developmental disabilities, and the other one is a long-term residential care institution for adults with psychiatric and neurological diagnoses. Mental hospitals, homes for elderly people and boarding schools are classical examples of what Goffman defined as 'total institutions'; the two organizations under study clearly fit into this schema. It should be mentioned here that the studies of special institutions for children or adults with disabilities in the Russian context are quite scarce. However, there have been studies that, while not focusing specifically on children with disabilities, have analysed the everyday life and practices of institutions with children left without parental care, revealing parallels with this paper in regard to the strategies characteristic of both children and staff (Astoyants 2006; Khlinovskaya Rockhill 2010).

In present-day Russia a considerable number of people with mental and multiple disabilities permanently live in large state-run residential care institutions (Klepikova 2017:22-23). These institutions are the only form of long-term residential facilities provided by the state for people with intellectual, mental or multiple disabilities. They were mostly constructed in the 1960s and 1970s, and remain a legacy of Soviet social policy. It should be noted, however, that isolating people with mental disabilities in large residential institutions was not unique to the Soviet and post-Soviet period; such institutions emerged in Western Europe and North America in the second half of the nineteenth century (Trent 1995).

Fieldwork was conducted in institutions with large facilities situated on the outskirts of St. Petersburg, where people live in quite crowded conditions, with one room housing between ten and fifteen residents at the time of research (2009-2011). I studied two different 'asylums.' The children's home housed 500 children at the time of research, the other, an institution for adults, housed about 1000 people. The majority of people with intellectual disabilities in Russia live at home with their parents, especially in the case of mild intellectual disability or autism that is discovered not when the child is born, but later in life. Children, who are institutionalised by the decision of their parents, stay in hospitals or residential care institutions for children under four years old, so-called 'baby homes', until they reach the age of four and then move to a specialized children's home (Disney 2017).

As for the facilities I studied, according to their official profile, specialized children's institutions accommodate children with confirmed 'mental retardation', an official diagnosis, widely used in the Russian medical and pedagogical discourses, that might be accompanied by other diagnoses - cerebral palsy, epilepsy, Down syndrome, autism, or visual and hearing impairments. 
Many of the young people left without parental care in childhood and graduating from the orphanages have the right to receive public welfare apartments. However, adolescents with disabilities rarely do so, as, firstly, in many cases psychiatric committees and court deem them legally incapable, barring them from certain legal rights. Even if they retain the right to legal capacity, the state 'socio-medical expert committee' often declares them unable to live independently. This is how most of end up at the residential institution for adults, a place they are likely to spend the rest of their lives. These institutions house a more diverse population.

The so called 'psycho-neurological' residential institutions for adults accommodate people with both psychiatric and neurological diagnoses, an approach inherited from the Soviet medical and welfare system. The residents' diagnoses include psychiatric disorders like congenital intellectual disabilities, schizophrenia, senile dementia, and purely neurological diagnoses like cerebral palsy or epilepsy. Thus, people with quite different intellectual abilities, and of quite different ages as well, live together behind the walls of the same facility. They are placed into these institutions not on the basis of their mental health state, but rather on their failure to take full care of themselves and live a completely independent life.

The personnel of the institutions who attend the residents daily include attendant nurses and medical personnel, and in the children's home there are also instructors in some groups of more active children. There is a substantial shortage of personnel in the institutions: for example, a group of thirteen children is taken care of by one attendant nurse, and there is one nurse servicing some eighty people in the institution for adults. Only a small part of the residents can fully care for themselves.

The orphanages and psycho-neurological facilities are 'closed' institutions, but since the mid-1990s some of them have partially opened their doors for NGO projects and volunteers. New attitudes towards people with disabilities began to take root around that time, and the processes of deinstitutionalization and inclusion started just some two decades ago, accompanying the socio-economic changes of reform. Changes in the attitudes towards children with disabilities, for instance, were reflected and documented in Svetlana Koroleva's and Alexei Levinson's paper (2010), whose research analysed the results of a survey conducted among the personnel of orphanages.

To gain access to the research field, I joined volunteer communities working inside the institutions. Volunteers are young people from Russia and European countries, who work with the residents on a day-to-day basis. Their actual responsibilities are not just to play with children or take adult residents for a walk, but feed, wash and dress them, compensating for the state personnel shortage. My role as a volunteer allowed me to participate in the everyday routines of the institutions, which meant that I could observe and analyse not just the official declarations and discourses on disability, performed by the 
staff of the institution or members of the NGO, but their practices and routines, their spontaneous behaviour and expressed attitudes.

People who take care of the residents were found to belong to one of the two communities. These communities are characterized by different discourses on disability and exercise two different sets of practices in their everyday routines. The practices and discourse of the personnel of the institutions illustrate the medical paternalistic approach to disability, typical for the state social welfare system. The volunteer practices and attitudes illustrate the ideology of 'normalization' (Nirje 1994). The NGO tries to transplant modern Western humanistic approaches to disability into the context of post-socialist care institutions. Volunteers implement the social model approach to disability according to which the limitations a person with disabilities suffers are not the direct result of their impairments, but have been imposed by the society in the form of stigmatization and exclusion.

There is a massive conflict going on between the personnel of the institutions and volunteers. It develops at the level of everyday interaction and practices, but has an ideological nature. Volunteers and personnel organize interaction with the residents differently in the whole variety of everyday contexts: during mealtimes, or hygiene procedures, or play, or education. The way they organize bodily contact with and keep their distance from the residents, the way and the frequency with which they address them, the nature of the judgments about their behaviour, the constructs of their clients' gender and age, assumptions about their abilities and possible careers, all differ substantially. This situation of conflict reveals the differences between the paternalistic and normalization approaches in a very distinctly maner (Klepikova 2017).

This paper aims at partially reconsidering the presumed 'totality' of these institutional environments by reviewing the totality of the control mechanisms, power relations, and standardization processes found within the special care institutions for people with disabilities at the level of routine interactions. Each organization coerces its members into acting in compliance with its logic and according to its rules, which was well shown in a seminal experiment by David Rosenhan (1973). In the course of the experiment a number of mentally healthy people imitated just one symptom characteristic of schizophrenia. They were all admitted to mental clinics, and although they demonstrated no symptoms after the admission, their behaviour that would have been seen as absolutely normal outside the clinic was interpreted as if they were mentally ill. However, while the inner life in a total institution is subject to strict official rules, it is of course not limited to them, and the ways those rules are handled and violated are of special interest to an anthropologist.

\section{The Underlife of Totality}

The crowded conditions of the institution determine the peculiarities of spatial organization: there are no places where one can be alone, beds stand side by side, there are no bed-side tables or private lockers. The absence of 
lockers means that there are no safe places to keep personal belongings, which in its turn implicates that a resident would not have many of them, and thus would not be able to present herself in socially desirable way. As one of few sociological studies of the psycho-neurological asylums in Russia has shown, although the residents internalized the existing discourse of disablement, they still demonstrated a great demand for more humanized and personalized approach, independence and personal space (Kos et al. 2009).

The shortage of personnel accounts for the lack of personal attitude, while the task of exercising control over large populations with scarce staff resources demands the regimentation of life. The temporal organization of life is one key implications: elaborate schedules of daily routines exist in both institutions that I studied, restricting times for bed and meals, as well as hygiene procedures or leisure. The need to constantly support the normal functioning of the institution by efforts of scarce personnel means that the institution has to develop certain mechanisms to compensate for this shortage. One such mechanism is designating power to privileged inmates over other inmates, who are tasked with everyday work duties. These duties include washing toilets, carrying heavy goods, bringing out waste, and caring for other, 'low-grade' residents. They either receive some small payment for their labour, or, more often, they are not paid but receive certain privileges, like more food or more access to the information controlled by the staff, and a higher status in the inmate hierarchy.

Another mechanism of control is punishments for wrong behaviour and violations of discipline. Punishments typically involve various limitations of mobility, like barring a resident from leaving her bed or going for a walk, and compulsory psychiatric treatment, such as giving residents sedative pills or sending them to the acute care department of a psychiatric hospital. The general goal of total institutions, according to Goffman (1961), is the resocialization of an individual who entered an institution in the status of an inmate, the elimination of previous identity(ies) and giving her a new one. Such a system of privileges and punishments is another typical feature of total institutions that accounts for the task of the resocialization.

The large populations of the asylums, however, are by no means homogeneous in the eyes of the people who work with them. As was mentioned, the institutional house residents have diverse diagnoses and are in quite different mental and physical states. Thus, we can meet a child with severe cerebral palsy, but 'average' intellectual abilities, a child with pronounced autistic features, who can walk, but does not use speech, or someone with mild learning disabilities that uses speech normally and can do a bit of reading and writing. In another room, we could find a deaf-and-blind child, a child who uses wheelchair to move and has moderate intellectual disability, a child who is completely paralyzed and has profound intellectual disability, all of ages from four to seventeen, living in the same room of the children's home. The fact that the institutional logic puts in the same room, as well as the totality of the paternalistic discourse 
on disability (as nurses would say, 'all of them are sick, deeply sick here, all they need is food and medication'), does not mean that they are not differentiated in the routine practices.

The differences are evident, for instance, at the level of unofficial classifications. In terms of the personnel of the institutions, the residents are classified into 'walkers', 'wheel-chair users' and 'bed-ridden' according to their physical abilities, while NGO volunteers prefer terms such as 'weak' and 'active', referring though to a resident's intellectual abilities in the first place, rather than the bodily characteristics. For each category of resident, their bodily and personality needs are interpreted differently by the members of the two communities. There are also other sub-categories, used mostly by the personnel, like 'pulpies' for children who do not chew food, or 'stinkies' for those who wear diapers. The residents who share the attendant nurses' routines and work for the sake of the institution are called 'helpers'.

Almost all the toys and clothes in the children's home are 'shared'. Even when a child receives an individualized present from volunteers, it is soon collectivized. While 'weak' children remain almost completely deprived of personal belongings, more 'active' children tend to enact various strategies, similar to those described by Goffman in regard to the patients of psychiatric wards, like creating stashes in the rarely accessed wardrobe shelves and concealing their personal items there. In Goffman's terms, such behaviour represents a type of 'secondary adjustment' to the total nature of the institutions. While 'primary adjustment' refers to the strategy of complying with the role of a patient or inmate, this type of behaviour seeks to deviate from this role and keep one's desirable self (Goffman 1961: 188-193; 306-320). However, for example the two 'active' adolescent girls, whose mothers visit them regularly, which is not the case with most of children at the orphanage, have a secure space full of personal belongings. Zhenia, who can fully control her arms and handle things with ease, has more personal items and can access them at any time, as she is allowed to have a bed-side table near her bed. Sonia, who has a more severe case of paralysis, can only access them with the help of nurses or volunteers, as her belongings are stored at a shelf hanged high up above her bed.

Apart from the folk taxonomy described above, adult residents fall into legally capable and legally incapable citizens, which to a large extent determines their access not just to legal rights in general, but to freedom of choice and available resources on the everyday interaction level. According to the law, the legally incapable status only limits a person's right to participate in legal contracts and transactions, like receiving one's allowance, selling property or getting married, but does not influence, for instance, a citizen's mobility. In practice, however, incapable residents of the institutions suffer from a variety of other limitations, including the fact that they are allowed to leave the institution only accompanied by a representative of the staff. This is rationalized by the administration in terms of 'being responsible' for a resident's life 
and actually means that such residents never leave the walls of the institution. The legally incapable residents of the institutions in most cases stay under the guardianship of the state institution. The law does not formally determine the one responsible person for those under state guardianship, but in practice the head of the institution is considered to be the guardian. The legally incapable residents can only leave the department where they live and, say, go for a walk in the yard with a volunteer, with personnel's permission. The legally capable residents are allowed to go out on their own, but are obliged to notify the personnel of their plans to leave the institutions and return before a certain time in the afternoon. All of these rules are not formal legal requirements: they are invented by the institution to facilitate control over the inmates, which is an intrinsic feature of total institutions.

These rules, however, are not applied universally. Some of the legally incapable residents, those who are more 'active' and do not use wheelchairs, are allowed to leave their departments whenever they want during the day time, with no special permission needed, while the 'weakest' are sometimes only allowed to leave their room if a volunteer insists. Some of the legally capable, especially 'helpers' do not have to ask permission to leave the institution each time and can return later, but others, especially 'wheel-chair users', might not get permission, or have to return by a certain time, or are only allowed leave the institution accompanied by other, more physically 'able' residents or volunteers. It is important to note that the existing rules are subject to negotiation. Thus, NGO representatives can persuade the staff to allow them to take a legally incapable resident out for an excursion. Or, one legally capable resident Rusanna often manages the agreements between her and the staff about the time when she has to return to the institution in the afternoon, just like a teenager negotiates and manages the time when she has to be back home with her parents.

Similar informal limitations and extensions affect the residents' rights to decide how they spend their disability pensions. Thus, Igor, who is legally capable, has average intellectual abilities, but very limited mobility, was talked into keeping his allowance money at the social worker's office, so that his money is not stolen. Though his money is in a 'safe place', he has to negotiate what he wants to buy with the social worker, and thus is more dependent on the staff than some other legally capable residents. At the same time, Olesya, a physically active 'helper', who was once legally capable and got used to spending her money at her own discretion, has more possibilities to choose what she wants to buy than most of the legally incapable inmates, because the social worker finds it appropriate to discuss her wants with her in more detail. In fact, belonging to different legal categories, Igor and Olesya have quite similar access to their financial resources and freedom of choice.

These examples show that in the routines of the institution the formal legal classifications are applied rather selectively and adapted both to the interests of the personnel and to the perceived benefits of the residents (say, 'safety'). 
Whether a limitation or extension would be applied in each case partly depends on the activeness and persistence of a resident herself. The distribution of meals is centralized, the food is administered to the wards at fixed time, and the 'total' character of the rules and standards mean that each resident should get an equal portion of the same food and drink. The nurses, however, vary the portions and kinds of food they distribute according to resident age, constitution, or ability to control their bodies, adjusting the fixed norms to the perceived needs of a resident or personnel's interest. They often take into account the preferences and tastes expressed by the residents as well.

Mealtime in fact remains the only strictly scheduled and implemented procedure, while other formal points of the schedule remain the responsibility of attendant nurses or instructors. Thus, a nurse at the children's institution might decide that it would be rational to put children to bed for a nap earlier, because it would allow the personnel to have longer rest themselves. Not every nurse would change children's diapers and provide hygiene procedures as scheduled; one would do it only once a day, instead of three as scheduled, and another as often as a diaper is full. What is deemed necessary for 'active' children, like play or a class with an instructor, might be viewed as an irrational and unreasonable effort investment in case of the 'weak'.

Physical exercise or walks, that occupy a line in a formal schedule, might be enacted and performed by the personnel only during the check-up visits of state inspectors, because the idea that physically 'sick', 'disabled' children might need physical exercise looks absurd for instructors. The same happens with formal sanitary rules and standards. For example, during the bath procedures it is impossible to accomplish all the formal sanitizing requirements in a scheduled period of time, taking into account that an attendant nurse at the children's institution has to wash thirteen children during one hour. The fact that some rules and requirements cannot be fulfilled impacts the personnel's attitudes towards the necessity to comply to the rules in general. Moreover, different nurses have different 'rules' they invented themselves: one would encourage that children empty their pots themselves, to develop the self-care skills, and the other one would strictly prohibit it, so that they do not soil themselves, just like in a family mother and grandmother might have different views on what should be allowed or restricted to a child.

Another context in which the personnel appeals to the formal rules is when they feel the need to beset a volunteer. For example, it is prohibited by sanitary standards to sit on a child's bed, but nobody pays attention to this rule until a conflict between a nurse and a volunteer happens, and then the rule is enacted. The differences between the declared rules and their practical implementations, omnipresent in the environments described in this paper, are illustrative of the Wittgensteinian idea of the rule-following paradox: the rule itself does not contain the rules for its implementation (Volkov 1998: 159).

The administered punishments also vary and highly depend on the will of a certain nurse or, in the institution for adults, a psychiatrist on duty. Some 
nurses never punish children, others 'punish' preventively, even if a child has not violated the discipline. The nurses are not unanimous in their understanding of 'discipline'. What is counted as misconduct and a violation of social order, and therefore subject to punishment or moral training in the context of special institutions in some cases differs from what we are accustomed to in the culture at large. Thus, the personnel of the institutions for adults usually do not interfere if a resident is masturbating publicly, which would be considered a violation of social norms outside the walls of the institution. Educating a grown-up person with an intellectual disability might be considered useless by the personnel. At the same time an attempt to stop a person with a psychiatric diagnosis who is suffering from social and sensory deprivation from a habitual calming action may result in a nervous breakdown, so not interfering with it is a practical choice determined by the specificity of the residents. Or another example: Pasha used to fall down and sit for long periods of time on the floor, while walking back and forth along the corridor. If we see a person falling down or sitting on the ground, we are likely to offer her help or set her back to her feet, or in case of a child tell her that she is misbehaving. But in case of Pasha it never happens. The staff of the institution and volunteers know that he needs to fall down and keep sitting from time to time because 'he's sick' in the discourse of the former, or 'he wants his body to feel better' as framed by the latter. In a manner of speaking, in some cases the environment of the institution is less norms-enforcing than the culture at large.

The limitations of freedom are not always framed as punishments or moral training, as we could have expected to happen in a coercive institution. In many cases in a psycho-neurological institution, various restriction devices are used to protect a person from self-harm, and the technologies here might be quite elaborate. Instead of using a straightjacket, the personnel may tie the arms of a resident in a way that would allow her the maximum freedom of movements, or put boxing gloves on his or her hands, which would be even less restricting.

The system of privileges has an important implication for the institutional hierarchy. Some of the top-positioned 'helpers' manage to receive even a higher status in the hierarchy and a career boost, receiving an official job-place. Thus, Tanya, a young resident of the institution for adults, has managed to become an attendant nurse, and although she is still highly dependent on the decisions of the chief physician, she has the power to negotiate and control a variety of decisions concerning the residents and the everyday life of the department where she lives and works. Tanya and other residents who gain similar positions may, at least in a number of contexts, become more powerful and informed agents than the members of the personnel, which blurs the difference between the two 'casts' and overturns the institutional hierarchy.

The process of 'resocialization' in institutions for people with 'mental retardation' has its peculiarities too. First, is that most of the residents of the category under study have been institutionalized since their early childhood, 
and 'socialized' as individuals fit to live within 'the system'. In contrast with army or prison or even a psychiatric hospital, they are not expected to leave the system of special institutions and live in the society, so there is no need to get them re-socialized. Since their infancy the children in the institutions are brought up in such a manner that they do not demand much attention from the personnel. If nobody reacts to a child's cry, her communicative intent is not going to develop normally, and the lack of communicative intent and agency make one a perfect, 'convenient' inmate who has internalized the rules to the extent that she does not need 'total' control.

This in its turn implies that the residents would be left both uncontrolled and unattended most of the time. For some of the 'active' residents, the lack of control means a certain degree of freedom. However, the lack of control and, therefore, reduced totality does not make the environment of the institutions more humane. One of the problems here is that unlike 'normal' adult people, small children and many people with intellectual disabilities, referred to as 'weak' in this paper, are unable to entertain and occupy themselves in a socially meaningful way, while those who have severe physical limitations cannot even change their position in bed without another person's help. In the situation the lack of attendance and attention many residents develop various forms of autocommunicative behaviour, habitually referred to by psychologists as symptoms of deprivation of human contact. These symptoms actually represent one of the 'primary adjustments' to the institutional environment. Volunteers try to challenge this situation by trying to make up for the lack of human contact and occupation, and offer another, more humanistic version of 'non-totality'. Apart from that, the symbolic boundary between the personnel and the residents is also blurred by the fact that the residents are not inanimate objects, and the personnel might develop human feelings for them, like sympathy or affection, making it impossible to perform the task of total control, and bringing human communication into being.

\section{Discussion and Conclusions: From Totality to Normalization}

In our everyday life, in contrast to the special care institutions under study, we do not eat, sleep and entertain ourselves in one same space with a dozen other people. We get up in the morning and do not remain in bed all day long, unlike many of the children and adult inmates of the institutions. We choose to have a full breakfast or just a coffee. We go to a school to study or work, and we get paid for the job we do. We vary our daily schedules, go to unplanned meetings at cafes, invite friends to a birthday party, or find a way to be alone, if we wish so. According to the normalization ideology proposed by the volunteers, all of these aspects of 'normal' life should, at least to an extent, be available to people with disabilities, including those who live in institutions. A day with a volunteer and a day without her might represent two 
different regimes for a resident: one full of play and exercise, the other entirely spent in a bed.

The efforts of the volunteers to create normalized environments inside the institution have important consequences for the total character of special institution. For example, the use of the alternative communication methods gives voice to the 'weakest' and 'hopelessly ill', from the point of view of the personnel. So as soon as children learn new communication skills, they start to ask for more. It makes them less 'convenient', less subject to the authoritarian decisions of the personnel concerning a variety of everyday issues. The same processes are going on in the institution for adults. For instance, the personnel of the institution used to call their adult clients 'children', as if to stress their dependent status, and the residents used to refer to themselves as children too. However, the NGO started to challenge these practices and attitudes. They try to persuade the residents of the institutions that they are adult people who are entitled to a higher level of independence in their decisions. The residents assume this concept quite eagerly as the adult identity provides them with an instrument to regulate the power relations with the personnel.

As Goffman has shown in his seminal essay 'The Interaction Order' (1982), in face-to-face communication we interact with each other as with a member of a certain broad category, a representative of a certain gender, age, social class, etc., who occupies a certain position in the social hierarchy that might be more or less powerful. At the same time, we act in response to the way our partner constructs the communication ad hoc. The residents of the institutions, although dependent for a variety of aspects on those who work with them, are by no means inanimate or completely powerless objects: they exercise certain levels of agency, intended or unintended. The nature and level of this agency to a certain extent determines the attitude of the personnel, which suggests that the degrees of 'totality' of routine decisions vary. The volunteers' ideology helps to enhance and promote the residents' agency, thus challenging the possibility of 'totality' by creating the niches of normalization inside the institution.

As the data from the special institutions for people with disabilities demonstrate, the 'totality' is manifested at the level of the structural organization of the institutions, institutional logic, and formal rules, but at the level of routine interactions the totalitarian approach is rarely exercised, and such interaction bears the features of 'normal' communication developing in normalized environments. The total control itself is virtually non-existent in total institutions: it is not essential, and moreover, it would be an excessive and irrational measure in the situation of the personnel shortage. The control over the inmates is only necessary to such degree as to guarantee that the social order is not violated.

Formal rules, and formal roles, that of an attendant nurse, for example, or a resident, are negotiated in the routine interactions. NGO volunteers become other powerful agents in the negotiation process. Formal rules, accounting for regimentation and totality, that are usually deemed irrational to follow, however, might be 
applied as a symbolic tool in regulating the power relations between volunteers and personnel. The inmates demonstrate primary and secondary adjustments to the institutional environment, but, as it becomes evident through the examples cited, the staff also adjusts to the specificity of the residents. The personnel apply the formal rules in accordance not just with their own practical convenience, but with the perceived needs of the residents or their expressed inclinations.

The application of the rules depends on a variety of common-sense decisions, or rather what rule is applicable in a particular situation depend on some implicit background knowledge. A rule does not provide an instruction for its application. The formal, declared rules might be strict and 'total' on paper, but in practice they are only enacted, so to say, ritually in the days of formal inspections, whose only goal is to ritually affirm the existing order. The concept of total institutions is an accurate and effective scheme, applicable for the analysis of certain kinds of organizations, communities and social environments. However, social facts that do not comply with this theory might be a far more challenging goal to study.

\section{References}

Astoyants M. S. (2006) Deti-Siroty. Analiz Zhiznennykh Praktik v Usloviyah Internatnogo Uchrezhdeniya. Opyt Vklyuchennogo Nablyudeniya [Children Left without Family Care. Analysis of Life Practices in Special Residential Institutions: A Participant Observation Experience]. Sociologicheskie Issledovaniya [Sociological Studies], (3): 54-63.

Disney T. (2017) The Orphanage as an Institution of Coercive Mobility. Environment and Planning A: Economy and Space, 49 (8): 1905-1921.

Goffman E. (1982) The Interaction Order: American Sociological Association, 1982 Presidential Address. American Sociological Review, 48 (1): 1-17.

Goffman E. (1961) Asylums: Essays on the Social Situation of Mental Patients and Other Inmates. New York: Anchor Books.

Khlinovskaya Rockhill E. (2010) Lost to the State: Family Discontinuity, Social Orphanhood, and Residential Care in the Russian Far East. New York: Berghahn Books.

Klepikova A. (2017) Social Construction of Mental Disabilities in Russian Residential Care Institutions. Public Health Panorama, 3 (1):22-30.

Koroleva S. S., Levinson A. G. (2010) Organizacii Negrazhdanskogo Obschestva. O Socialjnykh Formakh Zhizneobespechenija Detej-Invalidov v Sovremennoj Rossii [Non-civil Society Organization: On the Forms of Social Welfare for Children with Disabilities in the Contemporary Russian Federation]. Pro et Contra, (48): 42-60.

Kos A. V., Karpova G. G., Antonova E.P. (2009) Kachestvo Zhizni Lic s Ogranichennymi Vozmozhnostjami v Uslovijakh Prozhivanija v Internatakh [The Living Standards of People with Disabilities in Specialized Residential Care Institutions]. Zhurnal sociologii i socialjnoj antropologii [The Journal of Sociology and Social Anthropology], 12 (2): 131-152.

Nirje B. (1994) The Normalization Principle and its Human Management Implications. The International Social Role Valorization Journal, 1 (2): 19-23.

Rosenhan D. L. (1973) On Being Sane in Insane Places. Science, New Series, 179 (4070): 250-258. Trent J. W. (1995) Inventing the Feeble Mind: A History of Mental Retardation in the United States. Berkeley: University of California Press.

Volkov V.V. (1998)‘Sledovanie pravilu' kak sociologicheskaya problema [Rule-following as a Sociological Problem]. Sociologicheskiy Zhurnal, [Journal of Sociology] (3/4): 157-170. 